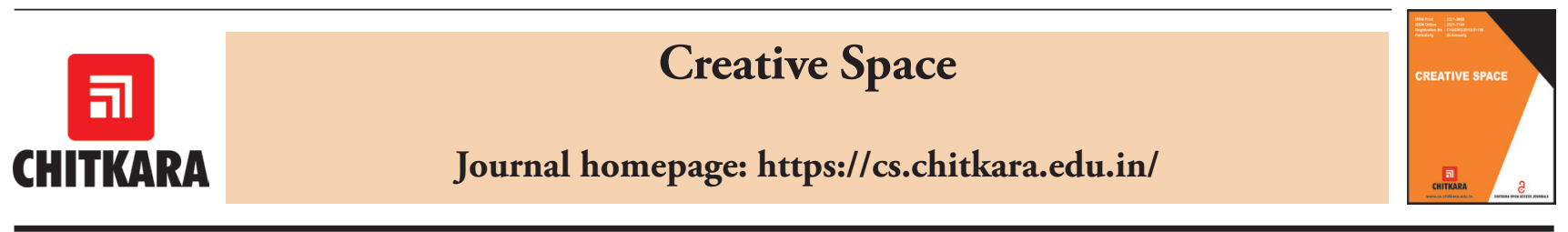

\title{
In Search of a Settlement Pattern for Bengal Delta Through Theoretical Re-Interpretations
}

\author{
Masud Ur Rashid 10 \\ Department of Architecture, Southeast University, Dhaka-1208, Bangladesh
}

masud.rashid@seu.edu.bd

\begin{tabular}{l} 
ARTICLE INFORMATION \\
\hline Received: September 16, 2020 \\
Revised: October 27, 2020 \\
Accepted: November 17, 2020 \\
Published Online: November 30, 2020 \\
\hline Keywords: \\
Bengal Delta, Rice-Cultivation Culture, \\
Settlement Formation, Settlement Evolution, \\
Core pattern
\end{tabular}

DOI: $10.15415 /$ cs.2020.81003

\begin{abstract}
The purpose of this study based on secondary source materials is to reinterpret and classify settlement typology that has relevance to the Bengal Delta. The theoretical analysis were used to figure out the Delta Settlement typologies and to study commonalities or core issues related to settlement formation. This desktop study together with available literature shows that many studies were carried out on the evolution of settlements and also on patterns of settlements. Globally settlements were seen to be fundamentally classified into two broad groups on the basis of their historic origin, that is, hunters and gatherers settlements and settled agricultural settlements. Among the settled agricultural pattern, there is a sub-group of wet-rice cultivation culture. Studies show that Bengal Delta typology is situated in a special thread of 'rain-fed rice cultivation culture' in the 'warm-humid' Bengal Delta region. With this textual footing, several conceptual ideas were evaluated and finally, the five principles of Doxiadis regarding the universal settlement formulation specifying the core components have been found relevant and also Mowla's hypothesis for settlement formation in the warm humid Bengal Delta has been found to be of relevance to explain the formation and evolution of the settlements model of the Bengal Delta found through the historic interpretation of old documents and subsequent studies.
\end{abstract}

\section{Introduction}

The Bengal Delta from an early age is being considered as a suitable geo-climatic location for the human colony to settle. Globally settlements were seen to be fundamentally classified into two broad groups based on their historic origin, that is, hunters and gatherers settlements and settled agricultural settlements (Schendel, 2009). Among the settled agricultural pattern, there is a sub-group of wet-rice cultivation culture. Studies show that Bengal Delta typology is situated in a special thread of 'rain-fed rice cultivation culture' in the 'warm-humid Bengal Delta' region (Khan, 1996). Apparently, there is no specific pattern or order in the settlements of Bengal Delta, yet settlements here are readily recognizable from other settlements in the world. That means certain unique attributes provides the 'identity' to the settlements in the Bengal Delta. If any settlement is needed to be studied, is to be studied in its context. Original order and pattern need to be traced back by having a clear understanding of the circumstances it has passed through (Mowla, 1990). The context affects the type of distribution, spacing and morphology of settlements (Hudson, 1976).

South and Southeast Asia is traditionally and culturally the home of rice cultivation. From the early records and phenomenological assumptions, it is observed that rice cultivation has shaped the original settlement pattern and morphology of the Bengal Delta (Khan, 1996). Crucial shift in the settlements occurred when agriculture evolved from shifting cultivation to rice cultivation on permanent fields. Settled life encouraged settlements based on geoclimate and availability of local materials, and with this, various relevant crafts also flourished. Barter trade between different products gave rise to certain places (hat) for the exchange of surplus goods. As a result, the earliest settlements and community life began in this region (Kavas, 2009).

In the case of vernacular settlements, housing has always been a direct expression of the responses to the geo-climatic context, state of know-how of construction techniques, and available local construction materials (Turner, 1976), Bengal delta is no different. With this local context, a certain housing and settlement pattern 
has evolved and with the change in the global context, in terms of technological, climatic, socio-cultural and economic factors, traditional architecture and settlement patterns transformation is taking place in the Bengal Delta also. Textual evidence suggests that radical changes started taking place in the settlement patterns only during the last one hundred years or so and this is more evident in the urban settings (Baqee, 2011). In this context, it is felt necessary to conduct some studies on the traditional settlement patterns in terms of their formation and evolution, in this region to create some baseline textual evidence to facilitate further in-depth studies on the settlement pattern.

\section{Objectives and Methodology}

The objective of this study is to identify the existence of any definable settlement pattern in the Bengal Delta through interpretations of secondary source, which are focused on settlement formation, evolution and pattern applicable to Bengal Delta. The methodology of this study focuses on the review of the published literature for a clear understanding of the concepts about the human settlement, tropical delta, rice-cultivation culture and the Bengal Delta as the focused context. Phenomenological and historic interpretation of the secondary source documents is used as the tool for this study. By this study, an attempt is made to explain the rain-fed rice cultivation based human settlements in the Bengal Delta and also to give a conceptual basis of the settlement pattern in the Bengal Delta.

For this study, authentic secondary sources of data included books, journal articles, documented conference proceedings, degree awarded dissertations, government publications, publications by NonGovernment Organizations and valid internet sources. Review of secondary source materials provides an understanding of the settlement pattern. Through analysis, some relevant concepts are picked up for further evaluation and to find their relevance with the Bengal Delta’s settlement.

The literature review provides a background knowledge base for inquiring and interpreting the human settlements in the Bengal Delta. Informed assumption is made from this study, by assuming that the present coastal area provides the analogous context of ancient Bengal Delta to study basic settlement pattern in the Bengal Delta.

\section{Bengal Delta and the Settlement History}

Deltas are the unique result of the interaction of rivers and tidal processes resulting in the sedimentary deposits in the world's continental shelf. Although comprising only $5 \%$ of the world land area, deltas have up to 10 times higher than the average population and agricultural production due to land fertility (Ericson, 2005). The major part of Bangladesh lies in the Ganges-Brahmaputra-Meghna Delta (GBM Delta), which in this paper is called Bengal Delta. It is the world's largest and the most populated delta (Ericson, 2005) and encompasses approximately 100,000 km2 of Bangladesh and West Bengal, India. Most of the delta population depend on water-based livelihood for their survival. 156 million people live in Bengal Delta, despite the tropical cyclones, tidal surges, floods caused by heavy monsoons.

Tropical coastal areas of the deltas present one of the most challenging settings given their diverse character and location at the land-water interface. These areas are home to large populated centres and are significant centres of agricultural production and development. Coastal areas of the tropical deltas also contain critical and sensitive ecosystems such as mangroves and a rich collection of flora and fauna induced cultural resources.

\subsection{Rice Culture in the Bengal Delta}

In Bengal Delta there is the environment of the floodplains with their frequent inundations and a humid tropical climate, both particularly unkind to material remains of human settlement in the remote past, not made of the sturdiest materials. Since stone does not occur naturally in the Bengal delta, early humans are likely to have relied on materials such as wood, bamboo and mud that did not survive the ravage of nature.

The prehistoric discoveries that have been made so far are almost exclusively from higher terrain surrounding the floodplains. Today the eastern hills of Bangladesh and the western plateaux (now in West Bengal, India) give the best clues to the early inhabitants of the region. Here stone, pebbles and petrified wood (fossil wood) were available. Fossil wood industries producing hand axes, blades and scrapers have been found in Lalmai, a small range of hills in Comilla district, Sitakund (Chittagong district) 
and Chaklapunji (Sylhet district). Archaeologists have linked these with similar tools from West Bengal, Bihar and Orissa (India) and the Irrawaddy delta (Burma). Evidence shows that the makers of these early tools were hunters and gatherers and survived by hunting animals/fish and gathering plants (Chakrabarti, 1992; Schendel, 2009).

Cultivation of plants and domestication of animals occurred well before 1,500 BC. The earliest evidence of settled agricultural communities comes from the old delta in West Bengal (Schendel, 2009). Here sites have yielded stone and bone tools, pottery with geometric designs, iron agricultural implements, domesticated rice and the bones of domesticated animals such as goats, cattle and buffaloes. On the basis of these findings, it seems likely that the subsistence base for people living on the poorer plateau soils was a combination of agriculture, animal husbandry, fishing and hunting, but that those living on the more fertile alluvial soils of the delta depended heavily on rice cultivation and fishing (Schendel, 2009). In this zone, a crucial shift occurred when agriculture evolved from shifting cultivation to irrigated cultivation on permanent fields. This type of agriculture became so productive that populations expanded and settled. Settlements grew and various supporting crafts also flourished (Schendel, 2009).

Originally a swamp plant, rice is extremely well suited to the ecology of Bengal Delta, where it is known as dhan (dhan = paddy) when unhusked, chaul (caul or cal) when husked and bhat when boiled. Generations of cultivators selected and adapted rice to suit their needs, especially with regard to resistance to disease, growing season and taste. In this way, they developed thousands of varieties to suit a multitude of local agro-ecological conditions (Khan 1991, Allison 2003). In the deltaic environment, special rice-species were evolved for different levels of flooding. Perhaps the most unusual is 'floating rice' (jalidhan), grown on low-lying land. This allows them to survive by floating in even 5-6m deep water. Historically, a pattern of land use developed in which the highest delta lands were reserved for homesteads and orchards (mango, jackfruit, coconut and betel nut). Slightly lower grounds were used to grow rice seedlings and vegetables, and middling and low lands for rice cultivation (Schendel, 2009). On middling lands, there were usually two rice crops: spring rice (aus, March to August), followed by autumn rice (aman, June to December). On low lands, with annual flooding, the main crop was autumn rice followed by winter rice (boro, February to April). These were associated with processing activities and festivities requiring certain types of space (Mowla, 1997 \& 1999b). The countryside became dotted with such specialized clumps of homesteads built around manmade ponds (pukur) that were used for drinking water, washing and fish-breeding (Schendel, 2009).

The success of rice-based deltaic agriculture provided the basis for sedentary lifestyles, which, by about the fifth century BC, led to urban centres, longdistance maritime trade and Bengal's first sizeable states.

Though in the same broader context, some dissimilarities are being identified between Northwest India and Bengal and Southeast Asia. No doubt, these are primarily conditioned on climate; in Bengal, it is the 'wet culture' while in Northwest India it is 'dry culture', former is the cradle of 'rice civilization' while the latter embodies "wheat and barley" civilization'. Due to being in the transitional zone between Southwest and Southeast Asia, Bengal delta has a lot of commonalities of settlement and other traits of Southeast Asia (Figure 1). A significant character being doted raised settlements amidst vast green paddy fields.

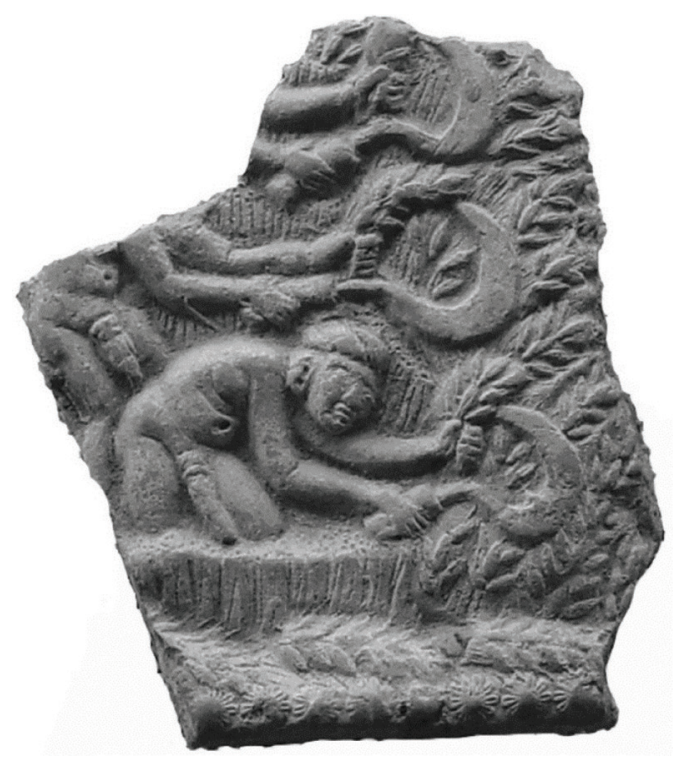

Figure 1: Harvesting. Fragment of a terracotta plaque, Chandraketugarh, First Century BC (Bertocci, 1996 extracted by Schendel, 2009). 


\subsection{Settlement in the Bengal Delta}

Geological evidence suggests that most of the regions of the Bengal Delta remained underwater during the Palaeolithic period and perhaps because of that humansettlements evolved in the adjacent hilly regions and valleys. Evidence of the antiquity of man in this region has been sought, therefore, not on the deltaic plains, but in the older geological formations. As the Delta extended by sedimentation process, the human settlement also gradually extended to plain land (Hunter, 1885) gradually receding from hilly areas. It may be assumed that by the late Neolithic Age, a substantial landmass must have been formed in the plains which made it possible for settled life between $1000 \mathrm{BC}$ and $300 \mathrm{BC}$ when the ancient janapadas flourished with mature cultural and political organizations in place. In this context of the ecologically induced process of land formation between the hills and the sea, it is not surprising that ethnically the majority of the people of Bengal Delta have more cultural affinity with the aboriginal peoples of the surrounding hills in the east than with the people of other regions in the west (Maloney, 1984). From the point of view of prehistoric intra-Asian cultural exchanges, Bengal not only came under the sway of an agrarian culture of Southeast Asia, but it was also is a 'shattered zone' which became a contact point between Southeast Asia and Middle-Ganga region of India. The process of assimilation of Southeast Asian Neolithic agro-cultural elements, such as wet-rice cultivation and Munda languages, to the Middle-Ganga region via the Bengal Delta, seems to have taken place well before the West Asiatic Neolithic cultural elements reached there via north-western India.

The people of Bengal Delta (basically Bangladesh) have never been able to lull themselves into a false belief that they controlled nature. They live in an environment where land and water meet and where the boundaries between these elements are in constant flux. As a result, settlement patterns have always been flexible and often transient in nature. From travelers' description and historical interpretation, the arrangement or composition of homesteads are thought to be guided by the topographical context (Figure 2). It is known from an early age, the copper-plate grants of the Palas, Chandras, Senas and other contemporary dynasties that the villages and towns varied considerably in size in this region. They appear to have been of one uniform pattern (Majumdar, $1929 \&$ 1943). There is evidence that they were usually of the 'nucleated', and not of the 'single farm' type. Thus, it appears that the rural population lived in lineage-based communities but in widely scattered habitation due to topography. Generally, the villages consisted of settlements or habitats (Vāstu), arable land (Kshetra), and natural meadow-land (go-chara) providing pasture for the live-stock usually located around homesteads or along the village boundaries. In most of the villages, there were pits and canals (garta and $n \bar{a} l \bar{a}$ ), barren tracts (ushara), tanks, cattle tracks (go-patha or go-mārga) or halots and paths. Some villages had periodic markets (hatta). The villages which were along the trade routes had bazars. A few villages are also stated to have been in the possession of woodlands or jungles (sa-vana, sa-jhātavitapa). As agriculture requires much water, most of the villages stood on the banks of rivers tributaries, canals etc. (Ray, 1993).

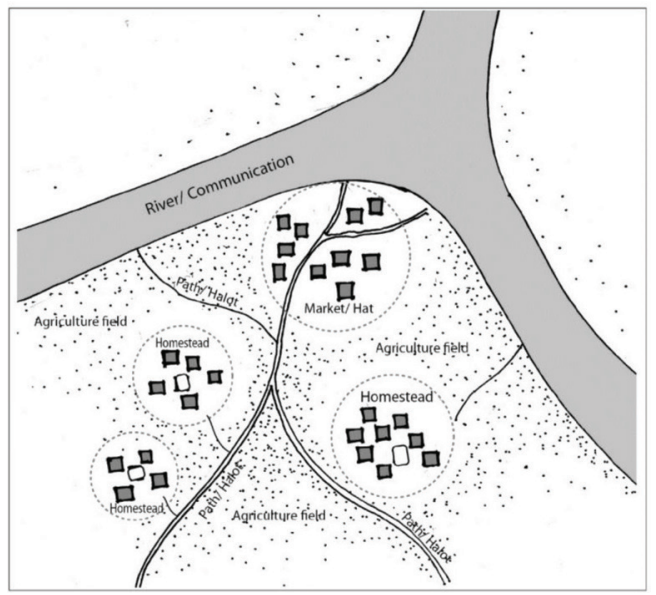

Figure 2: Schematic layout of settlement in the Bengal Delta based on Ray, 1993 and Mowla, 1997.

\subsection{Settlement in the New Delta}

The most significant characteristics of the New Delta or east Bengal floodplain settlements was that the settlement here did not evolve as a corporate social organization which gives a particular inhabited place continuity through the ages marked by intense interaction among its population and permanency. An important aspect of settlement here is spatial mobility and freedom due to the frequently changing course of rivers. In east Bengal, there was no fixed boundary of the neighbourhoods within the village and between two villages. The dwelling places or homesteads (Bari) were temporary huts (Ghar) made of 
mud, bamboo and thatch which could be dismantled and shifted away any time when needed. The temporary and perishable nature of the huts reflected the transitory nature of the villages which was without deep roots and the psychological attachment of its population with the place. This stood in sharp contrast from the most general characteristics of north, west and south Indian villages. In east Bengal abundance and easy availability of water, the most essential element needed for settlement's survival did not require cooperative and collective efforts to obtain it. Moreover, convenience of migration and building a new homestead within the region again and again due to innumerable and extensive waterways, loose communal and social organization, independence of the farmers in paying rents to the authorities and the frontier character of the settlements of East Bengal were largely responsible for giving birth to such transitory villages and loose social organization. This made the east Bengal villages elusive or unique (Figure 3) but still having a strong personality.

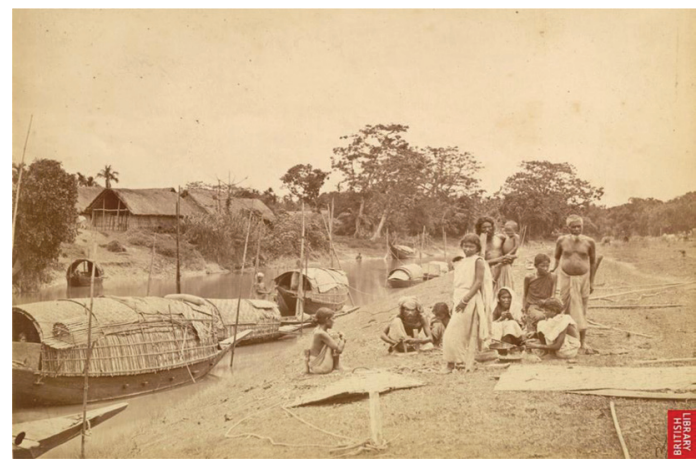

Figure 3: A Bengal village in the year 1860 (Source: British Library).

The east Bengal floodplain settlements did not lose its transient character even in the mid-20th century. The term 'elusive villages' was coined by the American anthropologist Peter J Bertocci in his study on the rural social organization of two Comilla villages in the 60s of last century (Bertocci, 1969). Absence of strong communal living and tradition-bound rural organization made the people of East Bengal atomistic, factionalist, averse to discipline and order, hedonistic and heterodox. Cooperation and collective action for attaining common goals or social capital were very weak among east Bengal population (Khan, 1987; Khan, 1996). They were least obedient to political authority, prone to anarchic behaviour and by nature rebellious. Mughal imperial chronicler of Delhi Abul Fazl described Bengal as 'a house of turbulence'. Interestingly he rightly ascribed the reasons for such behaviour of the Bengalis to the geo-climate of Bengal. The heat and humidity of Bengal were so tormenting to the central Asian Mughals that they called it 'a hell well-stocked with bread' (Fazl, 1579), that is there was no doubt about the fertility of this delta.

\section{Geo-climatic Characteristics of the Bengal Delta}

Bengal Delta (the Ganges-Brahmaputra delta) is also one of the most fertile regions in the world, thus earning the nickname 'The Green Delta'. The delta stretches from the Hooghly River on the west to the Meghna River on the east. The rivers, streams, and flood plain sediment (chars) are made up of a network of rivers. The Gorai-Madhumati River divides the Bengal delta into two parts: the young, vibrant, eastern delta and the older, less vibrant, western delta (Chowdhury, 2012).

\subsection{The Bengal Delta as a Land of Water and Silt}

The delta is huge because almost all water running off the Himalayas, the highest mountain range on earth, has to pass through it (Figure 4) (Steven, 1978) bringing huge siltation by which the delta is formed and stretches south. The Brahmaputra joins the Ganges in central Bengal and together they empty into the sea. Both rivers are truly gigantic; the Ganges is up to eight kilometres wide and the Brahmaputra spreads to the improbable width of eighteen kilometres (Schendel, 2009).

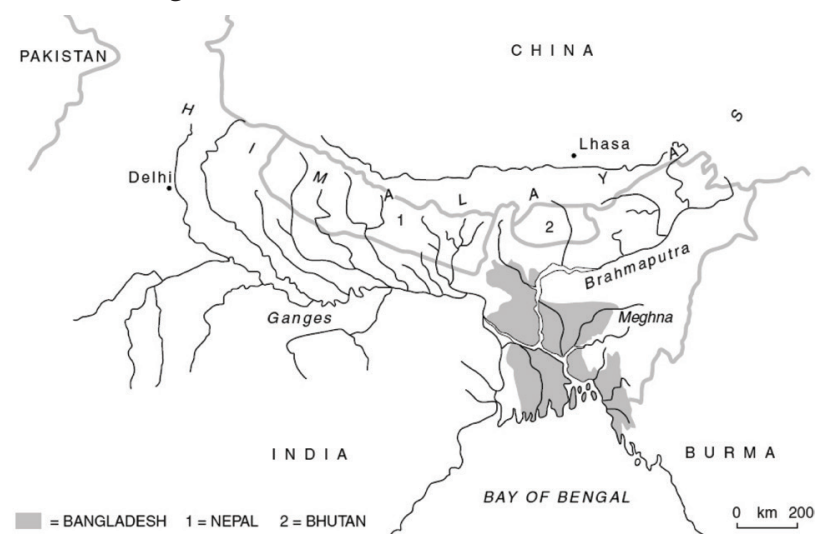

Figure 4: Map showing the catchment area of the Bengal delta (Source: Schendel, 2009).

\subsection{Livelihood with Climatic Vulnerability on Coastal Area}

Newly formed land in Bengal delta is less conducive to settlement and cultivation than old, degraded lands, 
due to the poor condition and salinity of new alluvia and continuous vulnerability to tidal surge and floods, along with the scarcity of domestic freshwater. Meeting on the banks of the seas is more important with time, as the people have to settle down in the lowlands, coastal zones, and islands vulnerable to tidal surges and floods to the edges of their climate as never before. In this way, some peoples are forced continually to put themselves dangerously in water's way. This is what is happening for centuries (Rashid, 2018). To respond to this context, the unique feature of Bengal delta settlements is the digging of ponds for sweet water and to raise the land for homesteading in the flood plains. The homesteads are surrounded by orchards to protect it from the high tropical winds.

\subsection{Origin and Evolution of Settlement in the Region}

According to Shirajul Islam Chowdhury (1988), based on history, "the settlement in Bengal started almost 20 thousand years ago on the hilly forests of South-East region". The interpretation of Chowdhury (1988) is also supported in the writings of Mohammad Habibur Rahman (1989). According to him, the elevated regions of North, West and East of Bengal were primarily the home of the present civilization (Rahman, 1989). According to Kosambi, contradicting Chowdhury (1988) and Rahman (1989), in the Bengal Delta, the commencement of agriculture and settlement on the river valleys and plane lands occurred on around 800 BC. The expansion of farming resulting in surplus resulted in the creation of a market-oriented economy (Baqee, 2011). Due to this huge success in agriculture, the Ganga river basin flourished with settlement and prosperity. Meanwhile, the tendency of private ownership of lands began to appear (Kosambi, 1965) giving some permanency to settlements. Due to the flourishment of farming, surplus goods were produced arousing the necessity of trade. To supply and exchange these surplus goods with distant settlements, ports were developed. The settlements or villages of Bengal were almost self-contained though not completely selfdependent, this is because some necessary items like salt, iron, etc. were not produced locally. They used to receive necessary items in exchange for surplus goods that they produced (Kosambi, 1965). From the very beginning, Kashi, Baranashi, Patliputra were developed as trade centres for agricultural resources, not for religious or administrative reasons (Chowdhury, 1992).

In the era Before Christ, the exchange centres were known as "Shongbaho" in Sanskrit. Generally, Shongbaho means "market town", where people from remote areas used to come to trade goods. According to Sen (1974), from 5th to 6th Century "Shongbaho" was known as "Bithi". In general, Bithi means a road lined or covered with large trees, actually most of the time, these exchange centres used to develop on roads like this as such they were named after it. The settlement that evolved almost twenty thousand years ago extended to the newly formed lands and got gradually transformed due to the many subsequent socio-cultural interventions, for instance, clustered, compact, linear etc. but in the core, they give similar character being from the same origin.

Three phases of the settlement process in Bangladesh were stated by Sultana (1993). Settlements were locally clustered on the highlands in the initial stage by avoiding low lands covered with dense forest but regionally yielding a localised pattern. The second one is the infilling stage when settlements were scattered to give a more dispersed regional pattern of settlements on the low lands of agricultural potential. The third and present stage is the stage of the competition which is brought for the excessive population growth during the last one century brought. In some areas with a normal pattern of settlement growth, land occupation in the limited land space results in high density. In Bangladesh, housing processes are a manifestation of the country's agricultural economy and have evolved in terms of physical and cultural structure.

\subsection{Factors for the Generation of a Settlement Pattern in the Region}

Aragones, Francescato \& Garling (2002) or Lee \& Parrott (2004) stated that the dwelling form and organization are influenced by the culture in which it develops and may be viewed to reflect the relationship between culture and environment. In case the of Bengal Delta Mowla (1999b \& 2019b) opined that hydromorphology has a profound influence on the social norms which in turn has been manifested physically in the settlement pattern of this region (Figure 5). The pattern of rural settlements in a certain area is the reflection of its economy, society, regional culture, its natural and ecological environment, and urbanization 
or agricultural extension. The evolution of the pattern of settlements is a process where old factors disintegrate, and new factors come into existence and sometimes become more influential, which finally leads to the coordinated development between the built forms and its surroundings. The pattern of settlement is the relationship between houses and buildings to one another. The connectivity develops according to geographical features, ways of living and lifestyles of each area. Housing and settlement condition depend on the economic and social state of households. The categories are affected by the local environment and construction materials which are available locally. There are two major groups of factors that affect the evolution of settlement. They are Geo-climatic and Anthropological factors

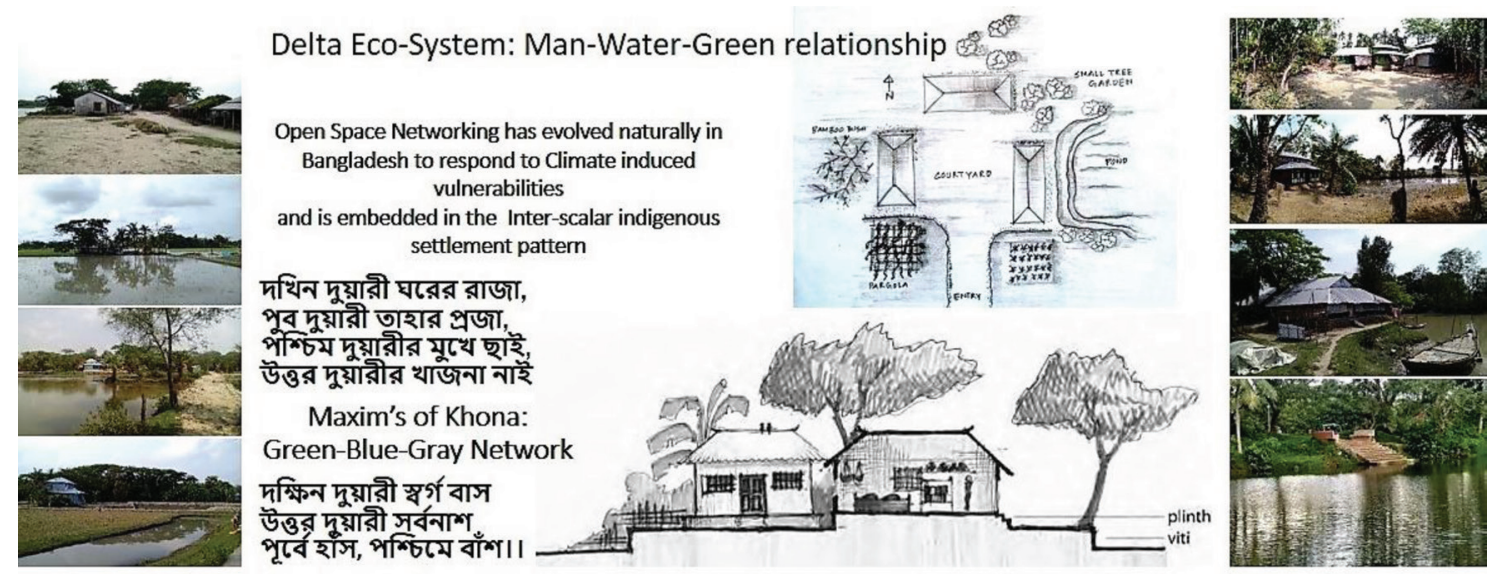

Figure 5: Hydro-Morphology has influenced the social norms which in turn has been manifested physically in the Bengal settlement pattern (Source: Mowla, 2019b).

\section{Formation of Settlements}

Libang et al. (2017) referred settlement as a place where people focus and settle down for living and production. According to the characteristics and sizes, settlements can be classified into two categories: urban settlements and rural settlements. In the $19^{\text {th }}$ century, the study on settlement geography started around the world. The relationship between settlements and the environment has since begun to be explored by several researchers. They have identified the association of settlement distribution with two basic resources water and land (Libang et al., 2017). Tan and $\mathrm{Li}$ (2013) found that the pattern of settlement has a close connection between the landform, the historical tradition, the agricultural system and the villages.

\subsection{United Nation's Concept of Settlement}

In 1976 the United Nation in Vancouver conference established the principles of human settlements, which included assessing a variety of previous elements housing, architecture, planning and their relationships, as well as other, practices such as environmental improvements and national as well as international growth etc. The Vancouver declaration lays down the following criteria for settlements:

...Human settlements means the totality of the human community - whether city, town or village - with all the social, material, organizational, spiritual and cultural elements that sustain it. The fabric of human settlements consists of physical elements and services to which these elements provide the material support...

The main physical components of a settlement are comprised of (Sarkar, 2010):

i. Shelter/ Dwellings, i.e. the structures of different shapes, sizes, types and materials erected by mankind for security, privacy and protection from the elements and his singularity within a community;

ii. Infrastructure, i.e. the complex networks designed to deliver to or remove from the shelter people, goods, energy or information;

iii. Services, cover those which are required by a community for the fulfilment of its functions as a social body, such as education, health, culture, welfare, recreation and nutrition. 


\subsection{Doxiadis' Theoretical Framework of Settlement}

C.A. Doxiadis (1968) rightfully declared that human settlements belong to the organic world. In his book, 'Ekistics' Greek architect C.A. Doxiadis (1968) outlined that human settlement consists of two major parts. One is the content (i.e. Man, alone and in societies) and the second one is the container (i.e. the physical settlement, comprising all-natural and manmade or artificial components). He subdivided them into five basic elements (Figure 6). They are:

i) Nature, providing the foundation upon which the settlement is created and the frame within which it can function.

ii) Man, (also referred to as 'Anthropos' or human) in an attempt to satisfy his biological and mental needs and his senses, it affects the environment.

iii) Society, Indicators such as social stratification, cultural trends, education, health and security, economic growth, law and administration are included.

iv) Shells, or the structures within which Man lives and carries out his different functions.

v) Networks, or the natural and man-made systems which facilitate the functioning of the settlement, for example, roads, water supply, electricity, etc.

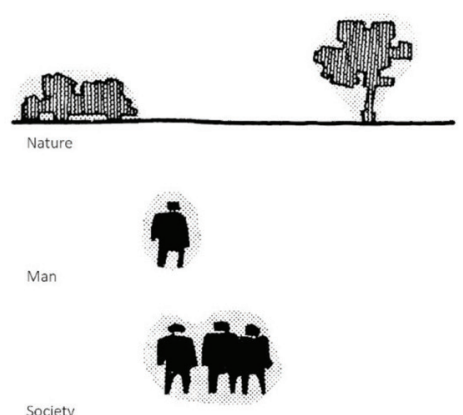

Societ
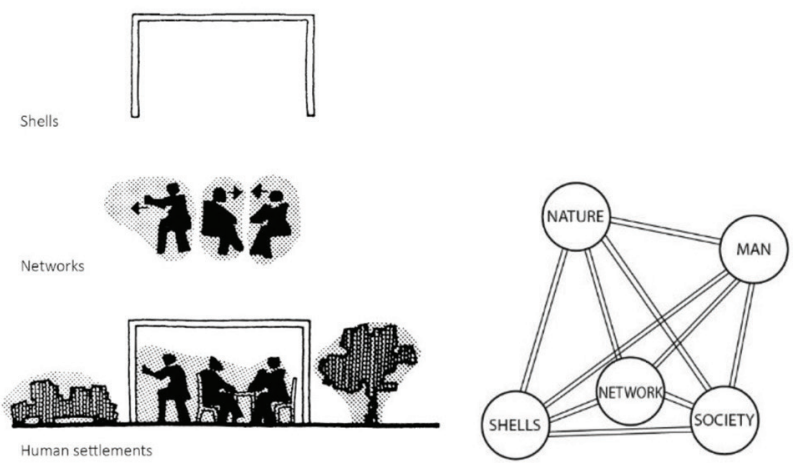

Figure 6: Schematic presentation of five elements of settlement by Doxiadis (1968, p. 22).
According to Doxiadis (1968), the relationship of man, society, shells (house), human contacts (paths) and nature promotes a basic settlement pattern. This concept is based on five principles: maximizing human potential; minimizing efforts (in terms of time, energy, money, routes); optimizing the protective space of human; optimizing the interaction between human and their environment; and optimizing the convergence of previous principles (Pertsemlidis, 2007; Hameed, 2020).

The study of the organisation of settlements has guided to conclude that throughout their total structure, they always consist of four parts: homogeneous, central, circulatory and special. These parts are derived from the five basic elements of the settlements. According to him, hypothetically any settlement consists of these four parts (with the elements of the house, agro-fields, barter trade, community and connecting path). i.e. Homogeneous part: fields, houses etc; Central part: built-up area; shops etc; Circulatory part: roads/ streets etc; and Special part: temple, school etc. These components and relationships remarkably fit with the settlements in the Bengal Delta, reconstructed from historic interpretations (Figure 2).

The descriptive analysis of human settlements often investigates the settlement's anatomy. It is possible to distinguish settlements according to their degree of functional homogeneity, the form and number of functions of the central area, the circulatory patterns contained within the settlement, or some special function or purpose observed in the settlement. At certain geographic scale, most human settlements contain a certain type of all these kinds.

\subsection{Parametric Representation of Settlement in Bengal}

Mowla's (2019b) parametric representation of the evolution of settlement pattern summarizes the similar issues as Doxiadis (1968) and hence illustrates the understanding of the growth of a settlement pattern along three major axes to enable explanation at various scales (Figure 7). This explanation of growth relationship also fits well with the settlements in the Bengal Delta, reconstructed from historic interpretations (Figure 2).

Human settlement is an organized colony of human beings consisting of shelters in which they live, work or enjoy and the circulation system that facilitates their movement. (Trewartha et al. 1967). Thus, the 
process of settlement inherently involves grouping of people and apportioning of territory as their resource base. One settlement is distinguishable from that of the other by their constituent attributes and growth pattern (Sultana, 1993). The schematic layout of the historic settlement in the Bengal Delta (Figure 2) seems to have an affinity with Doxiadis's principles (Figure 6) and Mowla's parametric evolution pattern (Figure 7), thus may facilitate its understanding and explanation with a further investigation (Figure 8).

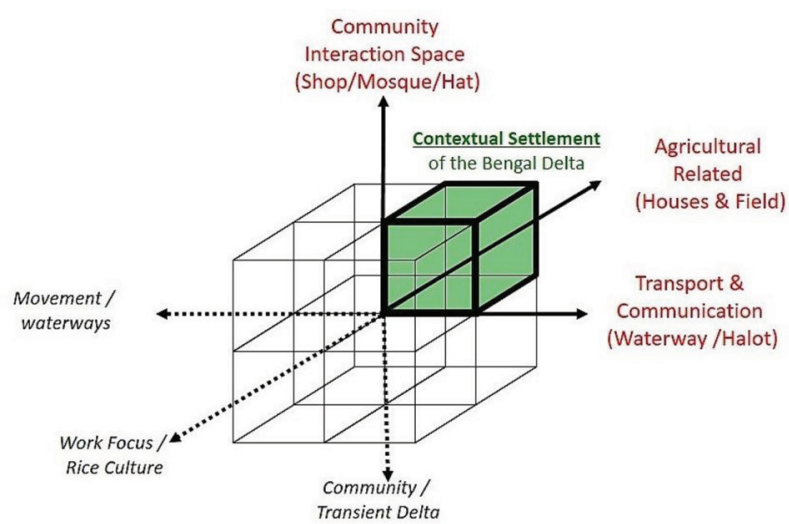

Figure 7: Parametric Representation of the growth pattern of a settlement i.e. Community, Work and Movement (Source: Mowla, 1990 and 2019b).

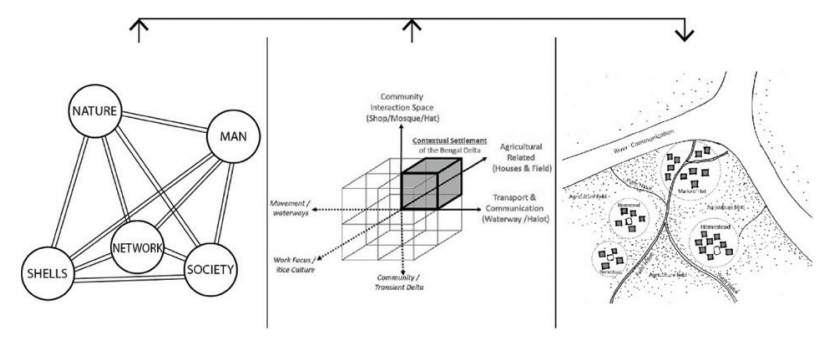

Figure 8: Explanation of the Bengal Delta Settlement pattern.

\section{The Bengal Delta Settlement}

Agricultural activities in low lying areas are dominated by rice farming during the wet season because of the persistent flooding or waterlogged conditions caused by monsoon rains that make it difficult to grow upland crops. The prevailing conditions in the Bengal Delta for thousands of years, trigger the settlement formation from the same common principles (Figure 8).

\subsection{Settlement Formation in Bengal}

The settlement system includes two different, but connected components: the way land is broken into owners and how owners manage to arrange buildings on their land. The size of the built-up area and the inter-house area thus decide the forms of settlement, but from the same common principles (Figure 8). Of course, farmland patterns are a core feature of landscapes and also significantly add to the character of a region (Kabir \& Mowla, 2012; Mowla \& Kabir, 2012). There are various factors and conditions responsible for different patterns of rural settlements (Mandal, 2001). These are:

a) Physical factors - nature of terrain, altitude, climate and availability of water;

b) Cultural and ethnic factors - social structure, caste and religion and

c) Safety and security factors - defense against the wild animal, natural hazard (storm, flood) and manmade offence (thefts and robberies).

However, $\mathrm{b}$ and $\mathrm{c}$ may be considered a by-product i.e. the pattern evolves from physical factors.

There is an overall hierarchical pattern within rural settlements in Bangladesh. It begins with a gram (village), composed of several Paras (neighbourhoods). This segmentation of a large village is often motivated by social and ethnic factors. Each Para again consists of a number of Bari (homesteads) usually established on raised land, which in turn are comprised of several Ghar (dwelling units of individual households within an extended family) and ancillary buildings typically arranged around a courtyard (Figure 9) (Hasan, D.M., 1985, Mowla, 1990, Rashid, 2013). Ponds are a ubiquitous feature of these settlement-providing water for domestic uses (Baqee, 2011). Until recently, ponds were the main source of drinking water in rural Bangladesh before the beginning of large scale sinking of tube-wells (Rasheed, 2008, p.204). The gradual elimination of ponds is transforming the earlier loose pattern into a more compact one.

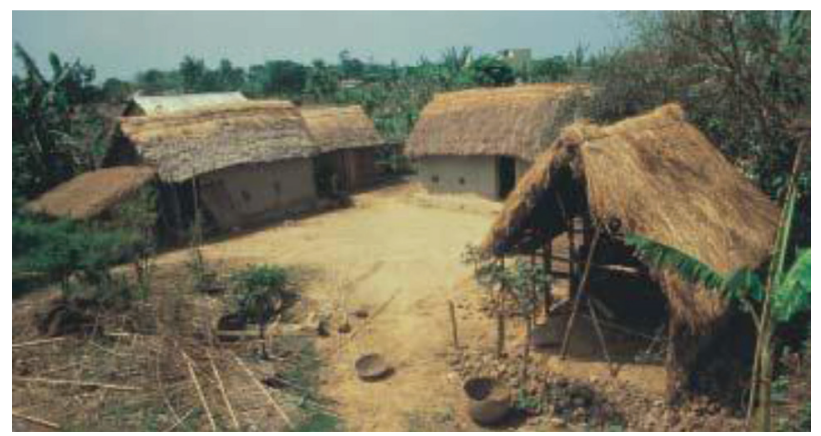

Figure 9: A typical courtyard in a rural homestead of Bengal (Source: Hasan, 1985). 


\subsection{Settlement Types in the Bengal Delta}

The pattern of settlements in any area refers to the spatial relations between one dwelling to another, i.e. whether they are located close to each other or they are further apart and if the spacing of dwellings exhibits any geometric form (Hudson, 1969 quoted in Rasheed, 2008). Rahman (1974) and Rashid (1991) identified three distinct variations of rural settlement in Bangladesh: Linear, Scattered or dispersed hamlet and Nucleated depending on topography and communication channel. On the other hand, Rasheed (2008) categorized rural settlements into two broad groups: clustered and dispersed where the linear pattern is a subtype of clustered settlement. Khan (1996) identified the linear and dispersed pattern of settlement which separated Bengal Delta from the other parts of the South Asian sub-continent. Mowla (1990, 1997) however, identifies only one pattern i.e. scattered clustered, which takes different shapes depending on geo-climatic circumstances. A serially cohesive unit is a gram/para with basic components of shelter/homestead (Ghar/bari), work area/ agricultural field/ water bodies; trade and commerce (hat/bazar); and circulation (path/ halot) (Doxiadis,1968) (Figure 6).

\subsection{Scattered Cluster}

Settlements take linear shape while evolving along rivers, roads or embankments. It is clustered shape when evolving on a natural higher ground. Mowla's (1997) hypothesis, therefore, fits better with the settlement pattern of deltaic rice-culture settlement. Which also showed that rural settlement pattern is generated from the social structure of rural livelihood. The basic components are homesteads (Ghar, Bari, Paribar), Neighbourhoods/Para (Morh, Path) and community area (Hat/Bazar) that consolidates in a tight urban context (Figure 10) and confirm with the principles of Doxiadis (1968).

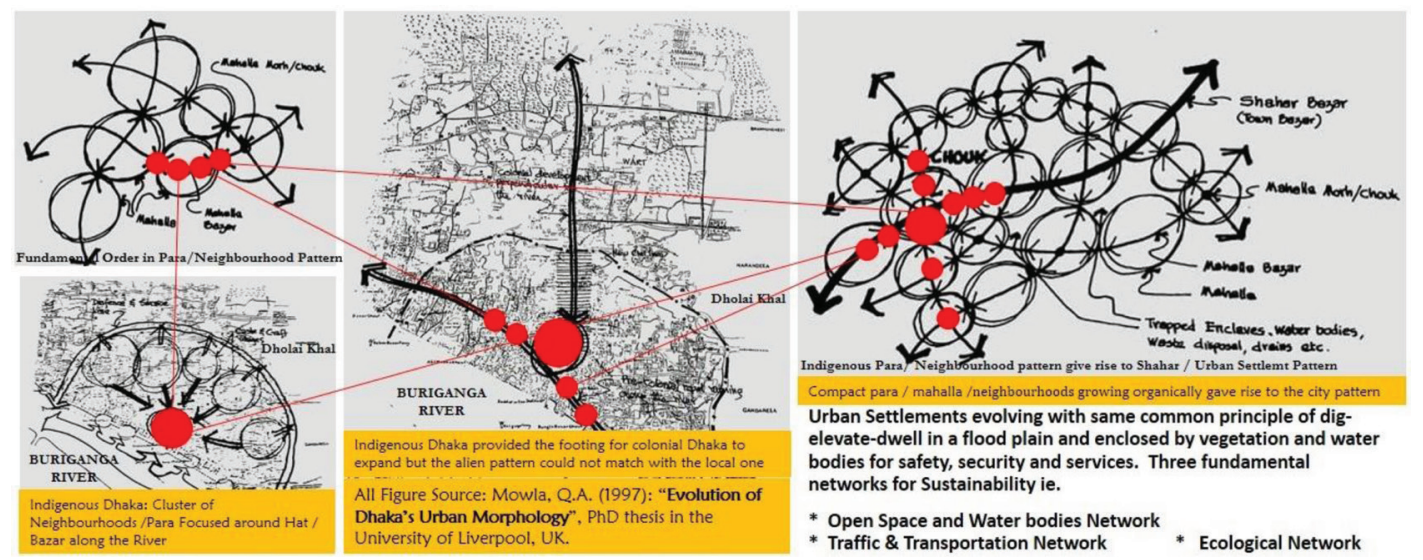

Figure 10: Basic Urban Pattern in this region has grown from the Context as can be evidenced in Bangladesh's primate city Dhaka (Source: Mowla, 1997, 1999).

\subsection{Anthropogenic Aspects in the Bengal Delta}

Bengal settlements have been described as elusive (Bertocci, 1996). They are not clustered around a central square, protected by defensive walls or united in the maintenance of joint irrigation works. Instead, they consist of spread out homesteads and small hamlets (para) perched on slightly elevated plots that become islands when moderate floods occur. Few dwellings are built to last, and traditional irrigation requires hardly any joint organization because it is largely rain-fed. Like the lie of the land changes in the active delta, villagers are often forced to relocate and rebuild their houses. Thus, nature's changing topography acts as a social and economic resource, and the mobile and fragmented nature of settlement has shaped the politics. Settlements of Bengal were not tightly organized communities under a single village head. Instead, they were dominated by continually shifting alliances of family and hamlet leaders. States seeking to control the population have always had to find ways of dealing with this flexible pattern of power-sharing adapted to life on the frontier of land and water.

\subsection{Spatial Aspects}

In the Bengal Delta, the rural cultures are tiny republics, Desai (1966) said. The towns are autonomous. By 
the self-contained villages, they will create everything important to lead their daily life by themselves. There is a system of setting down the periphery of a village. The borderline of a village is generally imaginary or marked either by river, hill and ridge or by trees, which means the natural features mark the boundaries. Apart from agricultural fields, sometimes roads, fields allocate the borderline. According to Apastamba scripture, a village consists of houses starting from $2 / 3$ to any number (Kher, 1973). Mowla (1990), however, identifies a village of about 80 to 150 households in a dense situation like Bangladesh although in the newly rising chars or coastal new settlements it may be much less (Figure 11). The smallest settlement in Bangladesh should have few homesteads (bari), their working grounds (agriculture fields or fishing grounds), a hat, and a circulation system between the components (Doxiadis, 1968).

In general, there is no fixed population of a village. In Bangladesh the names of the villages like TeGharia, PachGharia, Shatgharia, etc. show the layout of the household/population (Chowdhury, 1992). Small villages were known as "Gramak" and "Para" was called "Patak" or Hamlet in English. The basic group of indigenous homesteads connected both physically and socially is the core settlement pattern which may be termed as 'generic'. The boundaries of a generic settlement are not always administrative. Rather imaginary and social. They may not be under the same administrative unit of the union set by the state. There are some attributes for the generic indigenous settlements i.e. Sharing the same community space;
Sharing the same source of water or resources and Sharing the same space for the exchange of goods

These attributes and settings point to the earlier descriptions (Figure 8). Principles of Doxiadis (1968) and the hypothesis of Mowla (1990) seems to hold good but would require further studies for their validation in the Bengal Delta context. The literature review also gives clue to the concept that the principles that prompt generation of indigenous (rural) settlements also holds true for the consolidated (urban) settlements of the particular region (Figure 10).

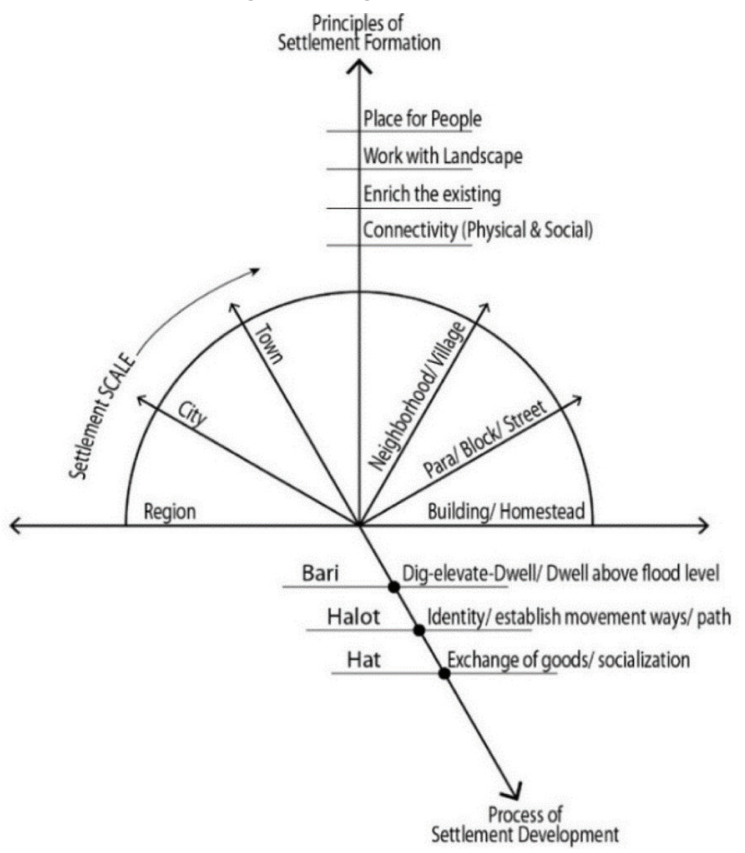

Figure 11: Diagrammatic representation of Mowla's (1990) narration about settlement.

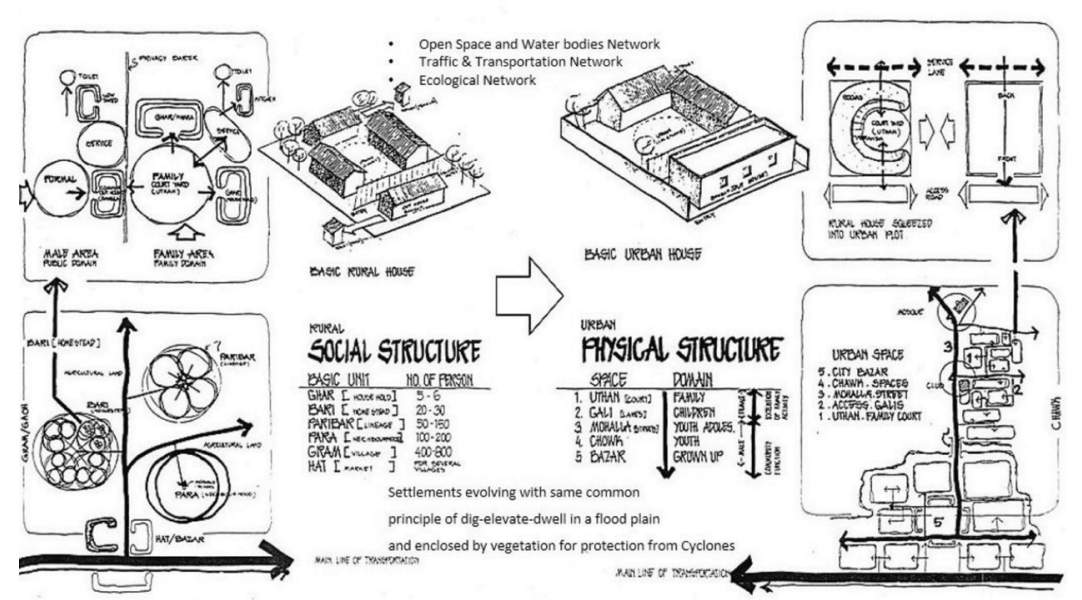

Figure 12: Settlements at various scale and levels, developing from the same common principles rooted in the context are sustainable (Source: Mowla, 1990 \& 1997). 


\section{Conclusion}

The desktop study and literature review reveals that many studies were carried out on the evolution of settlements and that universally the settlements can be classified into two broad groups, that is, hunters and gatherers settlements and settled agricultural settlements. Among the settled agricultural pattern, there is a sub-group of wet-rice culture and Bengal Delta settlement typology fits better with some special attributes of 'rain-fed rice cultivation culture' in a 'warm-humid' region. From the historic interpretations and phenomenological assumptions, it was argued that wet rice cultivation and processing has shaped the settlement pattern and morphology of this great delta. Settled life responded to geo-climate and availability of local materials; with this, various crafts also flourished. Barter trade gave rise to places (hat) for exchange of goods, thus earliest settlements and community life started in this region. The indigenous settlement is predominantly agricultural and residential, Shops are few and far between and the people getting their supplies at the periodical, weekly or biweekly markets (haat) to which people flock in from the neighbourhood. A clustered unit is laid out following the typography and the context giving rise to a settlement pattern which may be specifically attributed to Bengal Delta.

Settlements were scattered clusters taking different shapes depending on the context and were influenced by the way of life, environmental perception, aspects of behaviour, and sociological interaction and are the direct result of man's long relationship with his surrounding and represent the most natural and logical human response. Several components of settlements were identified, composed of house, field, market, community facility and circulation with recognizable local identity. The same pattern is loose in rural areas and compact in urban areas. When it is further densified, it is manifested in ribbon-like shopping streets with residential quarters behind.

\section{Acknowledgements}

The paper is based on the author's ongoing $\mathrm{PhD}$ studies in the Department of Architecture, BUET, Bangladesh.

\section{References}

Allison, M.A., Khan, S.R., Goodbred, S.L., \& Kuehld, S.A. (2003). Stratigraphic Evolution of the Late Holocene Ganges-Brahmaputra Lower Delta Plain. Sedimentary Geology, 155(3-4), 317-342. https://doi.org/10.1016/ S0037-0738(02)00185-9

Aragones, J.I., Francescato, G., \& Garling, T. (2002). Residential environments: Choice, satisfaction, and behavior. Westport, CT: Bergin \& Garvey.

Baqee, A. (2011). Grameen Bashati (Rural Settlement: Characteristics, Development and Planning Issues), Sujaneshu Prokashani, Banglabazar, Dhaka.

Bertocci, P.J. (1969). Pattern of Rural Social Organization in East Bengal. In A. Lipski (ed.) Bengal: East and West. Asian Study Center, Michigan State University.

Bertocci, P.J. (1996). Elusive Villages: Social Structure and Community Organization in Rural East Pakistan, unpublished $\mathrm{PhD}$ thesis, Department of Anthropology, Michigan State University, 1970; cf. Peter J. Bertocci, The Politics of Community and Culture in Bangladesh: Selected Essays, Dhaka: Centre for Social Studies.

Chakrabarti, D.K. (1992). Ancient Bangladesh: A Study of the Archaeological Sources. Delhi: Oxford University Press.

Chowdhury, Quader, S., Hassan, \& M., Qumrul (2012). Bengal Delta. In S. Islam \& A.A. Jamal (Eds.), Banglapedia: National Encyclopedia of Bangladesh (2 ${ }^{\text {nd }}$ ed.). Asiatic Society of Bangladesh.

Chowdhury, S.I. (1988). Arthanitik Bhugol: Visva O Bangladesh (in Bangla), Dhaka University, Dhaka.

Chowdhury, S.I. (1992). Bangladeshe Grameen Bashatir Bikash: Suchona theke Anumanik Choturtho Shotabdi Porjonto, Bangladesh: Bhougolik Shomikkha, Department of Geography, Bangladesh.

Desai, A.R. (Ed.). (1966). Social Background of Indian Nationalism. Bombay: Popular Prakashan.

Doxiadis, C.A. (1968). Ekistics, An Introduction to the Science of Human Settlements. Oxford University Press.

Ericson, J.P., Vorosmarty, C.J., Dingman, S.L., Ward, L.G., \& Meybeck, M. (2005). Effective sea-level rise and deltas: Causes of change and human dimension implications. Global Planetary Change, 50(1-2), 6382. https://doi.org/10.1016/j.gloplacha.2005.07.004

Fazl, A. (1579). Akbar Nama, translated by Henry Beveridge, vol 3:427.

Hasan, D.M. (1985). A Study of Traditional House Forms in Rural. Unpublished M.Arch Thesis. Bangladesh University of Engineering and Technology, Dhaka.

Hudson, F.S. (1976). A Geography of Settlements (2 ${ }^{\text {nd }}$ Edition). Macdonald and Evans. 
Hudson, J.C. (1969). A Location Theory of Rural Settlements. Annals of the Association of American Geographers, 59(2), 365-381. https://doi. org/10.1111/j.1467-8306.1969.tb00676.x

Hunter, W.W. (1885). Imperial Gazetteer of India (Vol. VI, pp. 24-28).

Kabir, S. \& Mowla, Q.A. (2012). Climate Change Vulnerable Community: A case for Coastal Bangladesh. In S. Osman, G. Saha, N. Uddin, N. Islam, A. Islam \& A. Alam (Eds.), Climate Change Impact and Adaptation (pp. 2-15). 3CSR-CE-DUET publication, Dhaka.

Kavas, K.R. (2009). Environmental Aesthetics of the Rural Architectural Tradition in the Mediterranean Highlander Settlement: The Case Study of Urunlu. Unpublished Ph.D. Thesis in Architectural History, Ankara, METU Graduate Institute of Social Sciences.

Khan, A.A. (1987). The Village in Bangladesh: A Survey. Bangladesh Journal of Public Administration, 1(1).

Khan, A.A. (1996). Discovery of Bangladesh. University Press Ltd., Dhaka

Khan, F.H. (1991). Geology of Bangladesh. Dhaka: University Press Limited.

Kher, N.N. (1973). Agrarian and Fiscal Economy in Mauryan and Post Mauryan Age, Delhi, Motilal Banrasidas.

Kosambi, D.D. (1965). The Culture and Civilization of Ancient India in Historical Outline. Routledge and Kegan Paul, London.

Lee, H.-J., \& Parrott, K. (2004). Cultural Background and Housing Satisfaction. Housing and Society, 31(2), 145158. https://doi.org/10.1080/08882746.2004.11430 504

Majumdar, N.G. (1929). Inscriptions of Bengal (Vol. III). The Varendra Research Society, Rajshahi.

Majumdar, R.C. (Ed.) (1943). History of Bengal (Vol. 1). Dhaka, University of Dhaka.

Maloney (1984). Tribes of Bangladesh and synthesis of Bengali culture. In M.S. Qureshi (Ed.), Tribal cultures in Bangladesh (pp. 33-35). Rajshahi University: Institute of Bangladesh Studies.

Mandal, R.B. (2001). Introduction to Rural Settlement (Revised and enlarged edition). Concept publishing company, New Delhi, India.

Mowla, Q.A. (1990). Study of Urban Development Opportunities for Lalbagh / Kotewali zone and Urban Design Vision for the land to be vacated by Dhaka Central Jail located at the study area. Unpublished Master in Urban Design Dissertation, University of Hong Kong.

Mowla, Q.A. (1997). Settlement Texture: Study of a Mahalla in Dhaka. Journal of Urban Design, 2(3), 259275.https://doi.org/10.1080/13574809708724409
Mowla, Q.A. (1999a). Urban Morphology: A Case of Dhaka and Khulna, Unpublished Research monograph with research grant from the Ministry of Science \& Technology, GoB, 1998-1999, Dhaka.

Mowla, Q.A. (1999b) Spatial Manifestation of Societal Norms: A Case of Urban Design in Bangladesh, Khulna University Studies, 1(2), 177-186.

Mowla, Q.A., \& Kabir, S. (2012). Response to Climate Change; Bangladesh Experience. In S. Osman, G. Saha, N. Uddin, N. Islam, A. Islam \& A. Alam (Eds.), Climate Change Impact and Adaptation (pp. 62-73). 3CSR-CE-DUET publication, Dhaka.

Mowla, Q.A. (2019a, February 09). Disaster Risk Reduction Planning in the Heritage Management. International Seminar-Workshop on Climate Change Agenda for Cultural Heritage, KU; UGC-BD; UNESCO (BD); ICOMOS (BD) and DoArchaeology-GoB, Bangladesh.

Mowla, Q.A. (2019b). Exploring for the Roots of Buildings and Settlements in Bengal. SEU Journal of Science and Engineering, 13(2), 16-23.

Pertsemlidis, C.R. (2007). The foundations of ekistics An attempt to test the validity of Anthropocosmos model in the context of modern evolutionary theory Purpose: The Anthropocosmos, pp. 1-15.

Rahman, G. (1974). Rural Settlement in Bangladesh. Studies in Bangladesh Geography, BNGA.

Rahman, M.H. (1988). Gonga Hribdhi theke Bangladesh (in Bangla). Bangla Academy, Dhaka.

Rasheed, K.B.S. (2008). Bangladesh: Resource and Environmental Profile. AH Development Publishing House, Dhaka.

Rashid, H. (1991). Geography of Bangladesh (2 ${ }^{\text {nd }}$ ed.). University Press Limited, Dhaka.

Rashid, M. (2013). The Role of Rural Home-Based Enterprises on the Housing Transformation in Sirajganj. Unpublished M. Arch. Thesis. Bangladesh University of Engineering \& Technology, Dhaka,

Rashid, M. (2018). Adaptation to Climate Change in the Built Form: Post Sidr Experience in Bangladesh, International Journal of Architecture, Engineering and Construction, 7(2), 10-18. https://doi.org/10.7492/ IJAEC.2018.008

Ray, N.R. (1993). Bangalir Itihash (2 ${ }^{\text {nd }}$ ed.), 1402 (B.S.)/1993.

Sarkar, A. (2010). Analysis of Human Settlement Patterns Using RS and GIS in the Plains of West Bengal. Indian Journal of Spatial Science, 1(1), 1-6.

Schendel, W.V. (2009). A History of Bangladesh. Cambridge University Press. 
Sen, S. (1974). Pracheen Bangla O Bangali (in Bangla), Kolkata: Bishwa Bharati Library.

Steven, G.D. (1978). The Ganges in Myth and History. Honolulu: The University Press of Hawaii.

Sultana, S. (1993). Rural settlements in Bangladesh: Spatial pattern and development. Graphosman, Dhaka.
Trewartha, G.T. Robinson, A., \& Hammond, E. (1967). Elements of Geography, MacGraw- Hill, NY.

Turner, J. (1976). Housing by people. Marion Boyars, London.

\section{药 \\ CHITKARA}

\section{Creative Space}

Chitkara University, Saraswati Kendra, SCO 160-161, Sector 9-C, Chandigarh, 160009, India

Volume 8, Issue 1

July 2020

ISSN 2321-3892

Copyright: [@ 2020 Masud Ur Rashid] This is an Open Access article published in Creative Space (Creat. Sp.) by Chitkara University Publications. It is published with a Creative Commons Attribution- CC-BY 4.0 International License. This license permits unrestricted use, distribution, and reproduction in any medium, provided the original author and source are credited. 